\title{
Concordar em discordar: análise discursivo-pragmática da polémica verbal em textos de opinião sobre o Acordo Ortográfico de 1990
}

\author{
Mariana Silva Ninitas \\ Universidade Aberta
}

\begin{abstract}
The main goal of this study is to analyze the construction of the polemical discourse, from a corpus composed by opinion texts concerning the Orthographic Agreement of 1990 (from now on OA90), taking into account the perspective of Discourse Analysis, Pragmatics, Rhetoric, Argumentation and Interactional Linguistics. The analysis of the corpus allows us to conclude that the speakers manipulate several strategies in the construction of their arguments, always with the intention of provoking and perpetuating the dissent.
\end{abstract}

Keywords: Discourse Analysis, Pragmatics, Orthographic Agreement 1990, Verbal Polemics

Palavras-chave: Análise do Discurso, Pragmática, Acordo Ortográfico 1990, Polémica Verbal

\section{Introdução}

O presente trabalho tem o intuito de analisar as principais estratégias acionadas na construção do discurso polémico num corpus de textos de opinião sobre o Acordo Ortográfico de 1990 (doravante AO90), nas perspetivas da Análise do Discurso, da Pragmática, da Retórica, da Argumentação e da Linguística Interacional.

Uma vez que o AO90 é, por muitos, considerado um ataque à língua portuguesa - ainda que este argumento possa ser rebatido pelo facto de se tratar de uma reforma ortográfica e não da língua - prevemos que o presente estudo contribua para a reflexão sobre a construção do discurso polémico em artigos de opinião sobre o AO90, redigidos em português europeu.

Tratando-se de um assunto particularmente polémico, o Acordo Ortográfico de 1990 foi alvo de inúmeras reflexões e críticas nas mais variadas plataformas de discussão. Neste sentido, para a prossecução do trabalho que pretendemos encetar, não é possível ignorar os contributos de Rodrigues (2008), sobre a estrutura da polémica verbal, em geral, e as polémicas verbais camilianas, em particular, de Gil (2018), sobre a polémica verbal em discurso referendário e político, de Ramos (2000), estudo que foca as características de polemicidade em discursos de opinião escritos, e de Cavalcante, Pinto e Brito (2018), texto que, centrado essencialmente numa perspetiva socio-cognitivo-discursiva para o estudo da argumentação em textos, visou refletir sobre as formas como a polémica, na sua vertente argumentativa, se materializou em textos mediáticos de natureza política.

Em particular, no que ao AO90 diz diretamente respeito, e ainda que elencar todos os estudos produzidos sobre a discussão linguística em torno das alterações ortográficas propostas seja uma tarefa quase impossível, é fundamental realçar o contributo de Ribeiro (1994), na perspetiva das Ciências da Comunicação, para a reflexão sobre a polémica em torno do Acordo Ortográfico, e a publicação de Seara e Marques (2015), que analisa a polémica em dois textos de opinião sobre o Acordo Ortográfico, numa perspetiva linguísticodiscursiva.

O presente estudo visa, pois, perceber de que forma se constrói o discurso polémico nos textos de opinião sobre o Acordo Ortográfico de 1990, identificando algumas regularidades na organização e funcionamento da polémica escrita. 
Concordar em discordar: análise discursivo-pragmática da polémica verbal em textos de opinião sobre o Acordo Ortográfico de 1990

\section{Questões de Investigação}

A um nível macro de análise, propomo-nos responder à seguinte questão:

- Quais os motivos que presidem ao dissenso e quais os argumentos que são convocados pelo autor?

Nível micro de análise:

- Quais os mecanismos discursivos que subjazem à construção do ethos do autor?

- Quais as estratégias de construção de polémica no discurso?

- Quais as estratégias discursivas predominantes de defesa e ataque (FTAs)?

\section{Corpus}

Dadas as limitações, para este estudo, com caráter exploratório, serão analisados dois textos de opinião sobre o Acordo Ortográfico de 1990, publicados na imprensa portuguesa, no jornal Diário de Notícias, em 2012.

Para melhor compreensão da análise, os textos estão identificados como "Texto 1" e "Texto 2", nos anexos, sendo convocada essa codificação, aquando da análise.

O seu autor é Vasco Graça Moura (3 de janeiro de 1942-27 de abril 2014), escritor, tradutor e político português que, após o 25 de Abril de 1974, se filiou no Partido Social Democrata, tendo exercido cargos de Secretário de Estado da Segurança Social e, mais tarde, dos Retornados. Durante dez anos (de 1999 a 2009), foi deputado no Parlamento Europeu. Em 2012, foi nomeado presidente da Fundação Centro Cultural de Belém, pelo Secretário de Estado da Cultura, Francisco José Viegas.

\section{Metodologia e perspetivas de análise}

Para a prossecução dos objetivos de investigação, os textos foram etiquetados tendo em conta o tipo de publicação a que se associam, a data e o seu autor (cf. Anexos).

Em termos globais, a análise do corpus sustenta-se no quadro teórico da Análise do Discurso (Maingueneau, 1991, 2002, 2005; Charaudeau \& Maingueneau, 2002, entre outros).

Uma vez que o corpus documental recolhido é constituído por textos de opinião - que contêm, em si mesmos, características dialógicas e dialogais in absentia -, a presente análise será igualmente subsidiária das teorias interacionistas de Kerbrat-Orecchioni (1980, 1992, 2001, 2005, entre outros), bem como das teorias de argumentação no discurso numa perspetiva retórica (Amossy, 1999, 2012), de que privilegiaremos a noção de ethos.

Será, igualmente, convocada a noção de face, proposta por Goffman (1967), que remete para a imagem que o interlocutor tem de si mesmo e que é construída a partir de atributos socialmente aceites (Goffman, 1967, p. 5), e de FTAs, ou seja, Face Threatening Acts ou Atos Ameaçadores da Face, previsivelmente, muito frequentes no discurso polémico.

A análise será, igualmente, subsidiária de contributos da pragmática, nomeadamente da teoria dos atos de fala, de Austin (1962) e Searle (1969). Nesta medida, identificamos como pertinente a proposta de tipologia dos atos ilocutórios expressivos, de Palrilha (2009), nomeadamente os atos expressivos avaliativos, que são realizados na expressão de opiniões favoráveis/desfavoráveis (Palrilha, 2009, p. 117-118).

Tratando-se de textos de opinião sobre um tema polémico, prevê-se que os mesmos possam conter reações a textos anteriores ou pretendam conduzir a reações futuras, que perpetuem a discussão e o dissenso. Por esse motivo, convocaremos as noções de atos ilocutórios de negociação de sentido, destacando os atos iniciativos (como a afirmação, a pergunta, a indagação) e os atos reativos (como a crítica, o desmentido, a refutação, a contestação, a contra-argumentação, a negação, a contraposição). 
Também a noção de implícito conversacional se revelará fundamental para a presente análise. Segundo Fonseca (1992), o poder do discurso não se esgota na palavra explícita, antes, sim, prolonga-se e amplia-se, por via da codificação do implícito (Fonseca, 1992, p. 368). Paul Grice, na sua obra Logic and Conversation (1975), evidencia a diferença entre a significação da frase e o sentido do enunciado. Na mesma linha, Duarte (2005) afirma que "o falante comunica quase sempre mais do que aquilo que diz e, às vezes, comunica diferente daquilo que diz" (p. 291), o que, na senda do defendido por Grice (1975), implica que o interlocutor recorra a processos de inferência para interpretar esses mesmos enunciados e os seus implícitos (agregados ao dito ou à enunciação). Ademais, "a interpretação de um enunciado faz apelo a um conjunto de premissas, sendo algumas de natureza cultural" (Mauai, 2015, p. 121). É, pois, no valor ilocutório (derivado e/ou implicitado) que o locutor calcula enquanto «ser do mundo» (Ducrot, 1980; Marques, 2000) e a partir do seu conhecimento enciclopédico (Kerbrat-Orechionni, 1986) o significado dos diferentes atos de fala.

Uma vez que o foco do presente trabalho é a polémica em torno do AO90, e considerando que a emoção é um dos traços caracterizadores do discurso polémico, a presente análise será igualmente tributária da noção de polémica de Amossy (2008, 2010, 2011), conquanto possam ser mobilizados outros contributos teóricos.

\section{Enquadramento socio-histórico do Acordo Ortográfico de 1990}

Conforme referido em Ninitas (2020), “em 1911, Portugal dá o primeiro passo efetivo no sentido de padronizar a forma de escrita da língua a ser usada nas publicações oficiais e no ensino" (Ninitas, 2020, pp. 1880-1881), através da criação de uma reforma que prevê um retorno à ortografia fonética da Idade Média (Castro \& Leiria, 1986), mais simplificada, alterando-se "a estética escrita do português" (Palma, 2010, p. 8). Tal movimento gera bastante discórdia, ainda que conte com nomes de grande prestígio como Carolina Michäelis, Adolfo Coelho, Leite de Vasconcelos, Cândido de Figueiredo e Gonçalves Viana. Fica, então, conhecida como a Reforma Ortográfica de 1911 ou a Reforma de Gonçalves Viana.

A polémica em torno da reforma em apreço faz com que a mesma não seja aceite de imediato, iniciandose, assim, aquilo a que Malaca Casteleiro e Dinis Correia apelidaram de a "guerra ortográfica dos cem anos" (Malaca Casteleiro \& Dinis Correia, 2007, p. 3).

Também no Brasil as vozes detratoras se fazem ouvir, considerando-a uma imposição unilateral e um ato de soberania por parte dos portugueses (Malaca Casteleiro \& Dinis Correia, 2007, p. 3).

Em 1911, ainda assim, Portugal adota a nova reforma ortográfica.

Em 1931, o primeiro Acordo Ortográfico entre Portugal e o Brasil, elaborado por iniciativa da Academia Brasileira de Letras, é aprovado pela Academia das Ciências de Lisboa, o mesmo, conforme referido por Ivo Castro, mas, segundo o mesmo autor, "parece nunca ter sido levado muito a sério" (Castro, 1987, p. xi). O Brasil mantém, desta forma, a sua antiga norma até 1938 - ano em que a Academia Brasileira de Letras consegue fazer aprovar a reforma vigente em Portugal (Ricardo, s/d, p. 9).

Em 1940, é publicado o Vocabulário Ortográfico da Língua Portuguesa, pela Academia das Ciências de Lisboa, e, em 1943, o Formulário Ortográfico, pela Academia Brasileira de Letras (Ricardo, s/d, p. 9).

As divergências, no entanto, conforme referido por Ninitas (2020), "fazem-se sentir com grande intensidade, ao longo dos anos, o que conduz à criação da Convenção Ortográfica Luso-Brasileira, em 1943, somente adotada em 1945, por Portugal, e que se manteve vigente até há poucos anos” (Ninitas, 2020, p. 1880).

Numa tentativa de acordo entre Portugal e Brasil, outras propostas são estudadas, mas somente no início da década de 70 se dá uma mudança. Segundo Estrela (s/d), em 1971, o Governo brasileiro dá o primeiro passo no sentido de uma unificação ortográfica com Portugal, nomeadamente, através da supressão do acento circunflexo na distinção das homógrafas (Estrela, s/d, p. 145). 
Concordar em discordar: análise discursivo-pragmática da polémica verbal em textos de opinião sobre o Acordo Ortográfico de 1990

Palma (2010) afirma, inclusivamente, que, em 1975, com o objetivo de aproximar as duas grafias, “a Academia das Ciências de Lisboa e a Academia Brasileira de Letras elaboraram um novo projecto de acordo, que nunca chegou a ser aprovado oficialmente, por razões de ordem política” (Palma, 2010, p. 13).

Segundo Ninitas (2020), “em 1986, juntam-se os representantes de Portugal, Brasil e cinco novos países africanos lusófonos - antigas colónias portuguesas” (Ninitas, 2020, p. 1880). Também neste encontro não há consenso, "incidindo a maior discórdia na problemática da acentuação de palavras" (Palma, 2010, p. 13).

Posteriormente, em 1990, a Academia das Ciências de Lisboa junta uma Nota Explicativa ao acordo original, documento que deveria ter entrado em vigor em 1994 (Ricardo, s/d, p. 10), mas a sua entrada em vigor é adiada, pois apenas Portugal, Brasil e Cabo Verde ratificam a sua aplicação (Cristóvão, s/d, p. 24).

Em 1998, é assinado um Protocolo Modificativo do Acordo Ortográfico da Língua Portuguesa, que retira do diploma original a data da respetiva entrada em vigor (Ricardo, s/d, p. 11). Em 2004, é aprovado em São Tomé e Príncipe pelos chefes de Estado e do Governo dos sete membros da CPLP um segundo Protocolo Modificativo, que estipula ser suficiente a ratificação por parte de três daqueles países para a entrada em vigor do novo Acordo Ortográfico. Nesta sequência, o Brasil ratifica o diploma e Timor-Leste adere ao mesmo (Ricardo, $s / d$, p. 11).

Em 2006, são depositados, no Ministério português dos Negócios Estrangeiros, os instrumentos de ratificação do Segundo Protocolo Modificativo, pelo Brasil, por Cabo Verde e por São Tomé e Príncipe.

Apenas em 2008, a Assembleia da República de Portugal ratifica o segundo Protocolo Modificativo (já autorizado pela Comunidade dos Países de Língua Portuguesa, em 2004). No mesmo ano, as reações detratoras ao novo acordo proliferam. Segundo António Emiliano (2008),

Para uma apreciação séria do Acordo Ortográfico de 1990 importa distinguir o acordo (que, juntamente com os seus dois protocolos modificativos, constitui um instrumento jurídico-diplomático que traduz uma intenção política) de reforma ortográfica que, a partir dele, se pretende impor em Portugal e alhures. A reforma ortográfica propriamente dita contém vinte e uma bases, a quase totalidade das quais se subdivide em diversos artigos e alíneas (não é uma reforma simples e inócua) e uma Nota Explicativa que é o único documento 'oficial' conhecido (de uma dúzia de páginas) que fundamenta a reforma do ponto de vista técnico $(2008$, p. 6)

Apesar da existência de inúmeras vozes contrárias ao AO90, o mesmo entra em vigor em 2009, em Portugal, iniciando-se, nesse ano, um período de transição e coexistência das duas ortografias (resultantes da reforma de 1945 e do acordo de 1990) até 2015 (Ricardo, s/d, p. 15). No ano letivo de 2011/2012 o acordo é adotado em todo o sistema de ensino e, a partir de 1 de janeiro de 2012, nos organismos oficiais. O Brasil, no mesmo ano, assina o decreto de implementação, com efeitos a partir de 2012.

Nesta sequência, e apesar de aparentar existir, finalmente, um consenso relativamente à implementação do novo acordo, em 2017, é criado um grupo de trabalho para avaliar os argumentos de defensores e detratores do Acordo Ortográfico (doravante AO).

Além das propostas do grupo de trabalho, a Iniciativa Legislativa de Cidadãos contra o Acordo Ortográfico entrega, em abril em 2019, na Assembleia da República, mais de 20 mil assinaturas. Esta iniciativa é assim transformada num projeto de lei para revogação do Novo Acordo Ortográfico.

A história da implementação ou revogação do Acordo parece não ter fim, mas é a partir dos sumarentos textos produzidos pelos defensores e pelos detratores que o presente trabalho será construído.

\section{Polémica}

A implementação do Acordo Ortográfico de 1990, conforme é possível verificar pelo acima exposto, está, desde o início, envolta em polémica. Nesse sentido, e com o objetivo de contextualizar o leitor quanto à noção 
de polémica por nós adotada, dedicar-nos-emos, no presente ponto, a apresentar algumas abordagens teóricas sobre o tema.

Rodrigues define a polémica como

[...] uma prática discursiva própria de interacções verbais marcadas por duas coordenadas constantes: a dissensão entre os falantes em relação a uma matéria e a dimensão argumentativa/refutativa determinada por objectivos persuasivos. Dessa prática discursiva fa[z]em parte, a par da polémica, a controvérsia, a disputa, a discussão, a querela, por exemplo. (2008, p. 30)

Maingueneau (1983, p. 20), por sua vez, defende que o discurso polémico se organiza a partir de dois polos antagónicos, em torno de um Nós e de um Eles/ Outro. A polémica seria, então, nesta perspetiva, uma dimensão específica dos textos de natureza argumentativa, cujo principal objetivo, mais do que levar ao consenso, passa por desqualificar um lado particular e tornar a tese impenetrável ao adversário (Doury, 2012), dando origem àquilo que Amossy (2010) classifica como a coexistência de dissenso.

Segundo Burger $(2005,2008,2011)$, é, então, no dissenso que os participantes negoceiam a coexistência dos opostos e a comunicabilidade, sempre conscientes da impossibilidade de um consenso.

O discurso polémico é, por isso, e como referido em Ninitas (2020), "percorrido pela isotopia do belicismo, em que as armas são as palavras. Estas armas servem para desqualificar o discurso do alocutário ou o próprio adversário (com ataques ad hominem)" (Ninitas, 2020, p. 1883).

Marc Angenot (2008, 2015), conforme referido em Ninitas (2020), classifica o discurso polémico como um diálogo de surdos ou uma retórica antilógica, na medida em que parece pouco provável persuadir o outro. É, por isso, e segundo o autor, "no dissenso que os intervenientes são conduzidos a uma forte carga emotiva, revestida de indignação e cólera" (Ninitas, 2020, p. 1884).

No caso particular do discurso de opinião, conforme referido por Fonseca $(1992,1998)$, é frequente que um discurso segundo responda a um discurso prévio (Maingueneau, 1984), estabelecendo, assim, uma relação dialógica e - talvez - dialogal in absentia.

Conforme referido, também, por Ninitas (2020), Amossy (2010, p. 209) nota "que o discurso polémico tem como principal objetivo a desqualificação do discurso do outro, acentuando as divergências. Assim, sem um contradiscurso não existe polémica. A natureza da polémica é dialógica, mas não necessariamente dialogal, já que o suporte de muitas das polémicas são os media" (Ninitas, 2020, p. 1884).

Kerbrat-Orecchioni (1980), por sua vez, acredita que a polémica seria um tipo de interação qualificado como agressivo, violento ou, eufemisticamente, vivo. É fundamental notar, também, que a polémica pode ser de ideias ou pessoal, sendo esta última revestida de ataques ad hominem, como o insulto e a contradição (Rodrigues, 2008; Jacquin, 2011). Jacquin (2011) alerta, no entanto, para a possibilidade de esses ataques poderem pretender atingir um elemento terceiro, ou seja, pode tratar-se, como referido por Ninitas (2020, p.1884), de uma jogada com "efeito", como numa partida de snooker. Brilliant (2011) defende, a este propósito, que nem sempre os argumentos provocam confrontos entre teses antagónicas e que o recurso à "opinião pública" se traduz em estratégias de posicionamento mais do que em confrontos ideológicos.

Destaque, no entanto, para o facto de a violência verbal, ainda que abundante no discurso polémico, não ser elemento fundamental na sua constituição. Não se trata, pois, e conforme referido por Gil (2018), de um elemento definitório da polémica, havendo necessidade de distinguir o que é violento do que é conflitual (este último, traço caracterizador da polémica) (Gil, 2018, p. 111).

A polémica pode ser construída com base em estratégias discursivas de agressividade ou violência verbais (Kerbrat-Orecchioni, 1980), avaliações axiológicas fortes e processos de desqualificação do discurso do outro (Amossy, 2010). Burger (2011) acrescenta, ainda, que o discurso polémico é tipicamente construído através de marcadores linguísticos de oposição e negociação. Neste sentido, Rodrigues (2008) afirma que o estudo da 
Concordar em discordar: análise discursivo-pragmática da polémica verbal em textos de opinião sobre o Acordo Ortográfico de 1990

polémica implica a análise dos atos de fala, dos atos ilocutórios ameaçadores da face, das marcas de subjetividade, das avaliações axiológicas, das retomas e da representação do Outro, e será nesse sentido que conduziremos o presente estudo.

Também o discurso direto, o discurso indireto e indireto livre, as citações diretas ou a reformulação constituem, segundo a mesma autora, formas de retoma do discurso do adversário com forte pendor argumentativo e polémico, através dos quais se realizam "actos de composição textual/discursiva com uma saliente natureza metalinguística/metacomunicativa” (Fonseca, 1994, p. 127-128). Ainda segundo Gil,

Se não conduz a uma solução, a polémica abre, pelo menos, caminho para a adopção de um posicionamento que impeça um infindável dissenso. Polemizar é, nesse sentido, uma actividade que está ao serviço de uma comunidade participativa e que reconhece a alteridade. (2018, p. 120.)

Segundo Dascal (2005, p. 30), as disputas têm uma função informativa, que permite aos intervenientes identificar, de forma clara, as diferenças entre as partes.

Segundo Ninitas (2020), "perante a multiplicidade de estratégias possíveis na manifestação da polémica, será fácil reconhecer e aceitar a, também, multiplicidade de vozes. Esta polifonia permite reforçar os laços e a identidade entre os diferentes atores - locutor e alocutário. Nesta perspetiva, o auditório a que se dirige o discurso é uma construção discursiva, pois o discurso do locutor tem de se basear nos saberes doxais, lugarescomuns e representações de que o seu alocutário/destinatário comunga" (Ninitas, 2020, p. 1886).

Fonseca, a este propósito, refere, ainda, que

partindo da imagem pré-existente do alocutário, o locutor assenta o seu discurso em premissas (de ordem social, cultural, histórica) que crê serem aquelas que correspondem aos saberes do seu auditório. O grau de dificuldade de tal tarefa varia em função da heterogeneidade do auditório; o locutor não pode, no entanto, eximir-se a essa construção discursiva, já que o alocutário/destinatário é parte integrante do dispositivo de enunciação. (1994, p. 124)

Amossy (2001, 2002) realça, não obstante, que a construção discursiva do alocutário (implícita ou explícita) é em uma estratégia argumentativa, que pode ir ao encontro da imagem favorável na qual se revê (Amossy, 2002, p. 469). As estratégias de referenciação, implícitas ou explícitas, dependem, no entanto, do contrato estabelecido entre os intervenientes, permitindo estruturar a prática discursiva em função dos constrangimentos impostos pela identidade de cada um dos intervenientes, bem como pelos objetivos, pelas circunstâncias (contexto), pelos topoi e pela doxa (Charaudeau, 1995b, 1995a, 2006).

A imagem do locutor, na mesma linha, segundo Ninitas (2020), "depende, igualmente, de construções discursivas e sociais, a que a noção de ethos não é alheia” (Ninitas, 2020, p. 1887).

Micheli (2011) acrescenta, a este propósito, que a legitimidade do ethos do locutor, aquando da interação dita polémica, pode ser construída pelo contraste entre a insensibilidade/desprezo do seu adversário em relação a determinado assunto e a consequente ideia de sensibilidade a que o locutor se associa automaticamente.

Em síntese, os estudos acima mencionados tornam claro que a polemicidade é uma dimensão específica dos textos de natureza argumentativa, que, em vez de pretender o consenso, visa a coexistência de posicionamentos antagónicos.

O estudo do discurso polémico, seguindo Rodrigues (2008), implica a análise dos atos de fala, dos atos ilocutórios ameaçadores da face, das marcas de subjetividade, das avaliações axiológicas, das retomas e da representação do Outro, e será nesse sentido que conduziremos o presente estudo. A polemicidade, segundo a mesma autora, é, então, um fenómeno pluridimensional "que pode constituir um traço configurador do discurso de forma generalizada ou de forma localizada” (Rodrigues, 2008, p. 70). 


\section{Análise}

O estudo exploratório que nos propusemos encetar prevê a análise de dois exemplares de textos de opinião acerca do AO90 (cf. Anexos), publicados no jornal Diário de Notícias, em 2012, cujo autor é Vasco Graça Moura.

Ambos os textos são férteis em passagens polémicas, que pretendem perpetuar o dissenso e dialogam com textos prévios. Vejamos, então, abaixo, algumas das estratégias manipuladas por Vasco Graça Moura.

\subsection{O Título}

O primeiro texto a analisar intitula-se "Intimação ao Professor Malaca". Somente pelo título, é possível antever o sentido do discurso que o autor adotará, não só pela presença do verbo "intimar" - que se reveste de uma natureza algo agressiva - como pela escolha da forma de tratamento "Professor Malaca". Comummente, conhecemos o Professor João Malaca Casteleiro pelos seus dois apelidos, o que nos leva a crer que a omissão do último nome tenha a intenção de provocar o destinatário.

O segundo texto, por outro lado, é um pouco mais opaco no que ao seu intento diz respeito, intitulando-se "Questões do Estado de Direito".

Vejamos, então, algumas estratégias convocadas pelo autor, aquando da explicitação do seu ponto de vista.

\section{2. $O$ Corpo do Texto}

Ao longo dos textos, o autor apresenta a sua opinião acerca do posicionamento dos seus opositores. Na verdade, como acontece em muitos textos "sobre o Acordo Ortográfico de 1990", o teor do discurso remete para um ataque $a d$ hominem, fazendo referência às características dos opositores e, em menor grau, às suas ideias.

(1) Num esgar de arrogância despeitada, o Prof. João Malaca Casteleiro diz ao Expresso de sábado passado, sobre a minha tomada de posição contra o Acordo Ortográfico: "É um autêntico disparate e uma atitude mesquinha, revelando espírito de vingança. Quem vai pagar estes custos?”. (Texto 1)

(2) Tenho pouca paciência para os trejeitos do autor de um livro intitulado O Novo Acordo Ortográfico, que não li, não tenciono ler e achei, de resto, perfeitamente detestável. Num gesto largo e moscovita, deixo essa ocupação para a moleirinha ociosa do Dr. António José Seguro que decerto muito lucrará com isso. (Texto 1 )

(3) O professor Malaca tem-se especializado em produções de medíocre qualidade, como o famigerado e redutor dicionário da Academia das Ciências, abominável exercício de encolhimento do português contemporâneo, de cuja revisão ele parece agora ter sido dispensado. (Texto 1)

(4) Não estando em vigor na ordem jurídica internacional, nem ele nem, por identidade de razão, o bizarro segundo protocolo modificativo, uma vez que também não foi ratificado por aqueles estados, o AO não está nem pode estar em vigor na ordem jurídica portuguesa. (Texto 2)

(5) Não existe. Qualquer outro vocabulário que se pretenda adoptar, seja ele qual for, será uma fraude grosseira ao próprio acordo. (Texto 2)

(6) Diga-se apenas que nem mesmo o Brasil aceita a carnavalização da grafia que está a ser praticada em Portugal! (Texto 2)

Confessamos, desde já, a dificuldade em selecionar apenas alguns exemplos de avaliações axiológicas explícitas, na medida em que tais manifestações proliferam ao longo dos dois textos. 
Concordar em discordar: análise discursivo-pragmática da polémica verbal em textos de opinião sobre o Acordo Ortográfico de 1990

No texto 1, efetivamente, essas avaliações são claramente dirigidas a Malaca Casteleiro ${ }^{1}$, ao passo que, no texto 2, essas manifestações se destinam, fundamentalmente, a Pedro Santana Lopes ${ }^{2}$, Jorge Bacelar Gouveia ${ }^{3}$, António José Saraiva ${ }^{4}$ e Henrique Monteiro ${ }^{5}$.

No exemplo (1), o autor começa por dar a sua opinião sobre o facto de o Professor João Malaca Casteleiro ter, também ele, dado a sua opinião sobre o autor. Começa, então, por referir que a sua atitude consiste num "esgar de arrogância despeitada", como resposta ao facto de o visado ter considerado que Vasco Graça Moura havia tido uma atitude mesquinha e vingativa. Percebe-se, desde logo, que os dois autores estabelecem, através dos seus textos, uma atitude dialógica, com um caráter agressivo, de alguma ofensa, diretamente dirigida às ações e às pessoas em questão. O caráter dialógico é, no presente excerto, bastante evidente e recorre a uma das estratégias mais explícitas, ou seja, a citação (Fonseca, 1994).

No exemplo (2), Vasco Graça Moura prossegue a sua apreciação sobre o Professor, confessando a sua falta de paciência para ler um livro que considera detestável - apesar de referir não o ter lido nem tencionar fazê-lo.

Através dos primeiros exemplos, compreende-se, de imediato, que não existe qualquer intenção de chegar a um consenso. O uso de violência verbal e de agressividade constituem, por si só, uma forma de perpetuar a polémica, em vez de procurar aplacá-la.

Vasco Graça Moura, ainda no exemplo (2), continua o seu intento de atingir o outro, desta vez, António José Seguro 6 , afirmando que o mesmo tem uma "moleirinha ociosa".

No exemplo (3), o autor desvia a atenção do seu discurso agressivo e foca-se no curriculum do Professor João Malaca Casteleiro. A este propósito, refere: “O professor Malaca tem-se especializado em produções de medíocre qualidade, como o famigerado e redutor dicionário da Academia das Ciências, abominável exercício de encolhimento do português contemporâneo, de cuja revisão ele parece agora ter sido dispensado". A negrito, destacamos algumas das avaliações axiológicas atribuídas ao percurso do Professor, que parece querer, acima de tudo, desqualificar o adversário e, consequentemente, o seu posicionamento - conforme, de resto, já é previsto por Amossy (2010) e Doury (2012).

Nos exemplos (4) e (5), por outro lado, Vasco Graça Moura tece algumas considerações sobre a criação de um Protocolo Modificativo ao AO90, referindo tratar-se de um ato "bizarro" e de uma "fraude grosseira". Ainda assim, não é possível ignorar que também esses comentários contêm, implicitamente, um ataque a quem o produziu e defende. Afinal, como referido por Fonseca (1992) e Duarte (2005), dizemos sempre mais do que aquilo que efetivamente dizemos e, por vezes, dizemos coisas diferentes do que aquilo que dizemos.

No exemplo (6), Vasco Graça Moura recorre ao conhecimento que pressupõe termos sobre a importância do Carnaval no Brasil, tecendo considerações sobre a brincadeira que acredita ser a implementação do AO90, brincadeira essa que nem o Brasil - que aceita qualquer Carnaval - parece querer adotar.

Ao longo de ambos os textos, é, pois, possível observar um conjunto numeroso de expressões agressivas, do qual se destaca, também, o uso da ironia. Vejamos, então, os exemplos abaixo.

(7) Prefiro poupá-lo aos custos desse ingente esforço intelectual. (Texto 1)

(8) Caridosamente, informo-o de que não vale a pena fazer batota...(Texto 1)

\footnotetext{
${ }^{1}$ Professor, investigador e linguista português, João Malaca Casteleiro participou nos trabalhos que conduziram ao Acordo Ortográfico de 1990 .

${ }^{2}$ Advogado e político português. Foi primeiro-ministro de Portugal, entre 2004 e 2005 . Foi, igualmente, o líder do partido Aliança até 26 de setembro de 2020. É um defensor do AO90.

${ }^{3}$ Jurista português, professor catedrático de Direito, advogado, jurisconsulto e árbitro. É um defensor do AO90.

${ }^{4}$ Professor 'Emeritus' e Historiador de literatura portuguesa. É um defensor do AO90.

${ }^{5}$ Jornalista português. É um defensor do AO90.

${ }^{6}$ Político português, membro e antigo Secretário-geral do Partido Socialista. Em agosto de 2011, havia sido eleito Conselheiro de Estado pelo Parlamento português. É um defensor do AO90.
} 
(9) Nenhuma das individualidades referidas toma posição quanto a esta situação paradoxal de que, certamente, tiveram a argúcia de se aperceber. (Texto 2)

Nos exemplos acima, percebemos rapidamente que Vasco Graça Moura usa expressões irónicas como forma de atingir os adversários. No primeiro texto, opta por referir, quase com condescendência, que poupará o opositor ao esforço de pensar ou alerta-o, caridosamente, para o facto de não ser possível fazer batota. Tanto num caso como noutro, o autor carrega o texto de implícitos, como a intenção de chamar burro ao opositor ou a insinuação de que, apesar da sua vontade, não será possível, a Malaca Casteleiro, fazer batota. A agressividade e a intenção de perpetuar a polémica, nesses casos, é evidente.

No exemplo (8), relativo ao texto 2, Vasco Graça Moura começa por "provocar" os adversários - neste caso, Pedro Santana Lopes, Jorge Bacelar Gouveia, António José Seguro e Henrique Monteiro -, tratando-os, ironicamente, como sendo "individualidades", no sentido de serem pessoas distintas, merecedoras de deferência. O autor opta, ainda, por destacar o contraste entre a deferência que, teoricamente, tais figuras merecem e o implícito de que, ainda que sendo sua obrigação, pela responsabilidade que tal importância pressupõe, nenhuma dessas figuras tomou qualquer posição, ainda que em posse de todos os dados.

Vejamos, agora, mais alguns exemplos que permitem identificar outras estratégias manipuladas pelo autor.

(10) $\mathrm{O}$ art. $^{\circ}$ 2. ${ }^{\circ}$ do $\mathrm{AO}$ dispõe: "Os Estados signatários tomarão, através das instituições e órgãos competentes, as providências necessárias com vista à elaboração, até 1 de Janeiro de 1993, de um vocabulário ortográfico comum da língua portuguesa, tão completo quanto desejável e tão normalizador quanto possível, no que se refere às terminologias científicas e técnicas." (Texto 1)

No exemplo (10), podemos observar uma outra estratégia utilizada pelo autor dos textos, como forma de validação do seu ponto de vista: a lei. Ao parafrasear a lei, o autor pretende fazer com que a sua tese seja impenetrável e, por isso, impossível de ser derrubada pelos opositores.

(11) Sendo certo que o prazo inicialmente referido foi modificado, deve o professor Malaca responder sem subterfúgios onde é que está esse vocabulário comum. (Texto 1)

(12) Sendo assim, é o professor Malaca intimado a esclarecer, imediatamente e sem subterfúgios, se a aplicação de uma ferramenta de conversão automática que elimine na prática a possibilidade de opção entre essas facultatividades corresponde a cumprir o AO. (Texto 1)

Nos exemplos acima, o autor recorre a atos expressivos iniciativos de pergunta, neste caso, instigando, de forma algo violenta, o seu adversário a responder às questões que, superiormente, coloca.

Repare-se no uso da modalidade deôntica em "deve o professor Malaca" ou na formalidade da construção em “é o professor Malaca intimado a esclarecer". Tanto num caso como noutro, a opção por uma abordagem algo agressiva, de exigência, que esclarece o leitor quanto ao ethos adotado pelo autor - um ethos de superioridade moral e, também, intelectual - não visa um consenso. Pelo contrário, pretende, ainda que pareça dar oportunidade de resposta ao opositor, através de um discurso de caráter dialógico, ofendê-lo e diminuí-lo em relação a si.

Ainda no que diz respeito ao ethos de superioridade assumido pelo autor, veja-se o exemplo seguinte.

(13) Também não vale a pena tratá-lo como interlocutor capaz quanto a questões jurídico-constitucionais relativas à recepção na ordem interna dos tratados e convenções internacionais. Prefiro poupá-lo aos custos desse ingente esforço intelectual. (Texto 1) 
Concordar em discordar: análise discursivo-pragmática da polémica verbal em textos de opinião sobre o Acordo Ortográfico de 1990

O autor, recorrendo a um dispositivo de ironia, coloca-se numa posição superior e capaz de tecer juízos sobre a capacidade intelectual do seu opositor. Assim, e de forma agressiva, o autor implicita que, para que o seu interlocutor compreendesse questões jurídicas, teria de encetar um considerável esforço intelectual, pelo que o poupará a tal exercício. Uma vez mais se percebe que não é intenção de Vasco Graça Moura chegar a qualquer consenso com o seu destinatário - afinal, quais as tréguas possíveis perante ofensas desta natureza?

$\mathrm{Na}$ mesma linha, o autor manipula uma estratégia muito interessante, que parece implicitar, precisamente, que o seu adversário é intelectualmente inferior e, por isso, será preferível repetir a informação. Vejamos:

(14) ... continua a ortografia que se pretendia alterar. (Texto 2)

(15) ... continua em vigor a ortografia que se pretendia alterar por via dele. (Texto 2)

Nos exemplos acima, o autor repete, em vários momentos, o mesmo discurso - ou variantes similares quase como cumprindo o velho ditado "água mole em pedra dura...".

\subsection{Fecho do Texto}

Por fim, analisaremos dois exemplos de sequências de fecho, presentes em ambos os textos.

(16) E por fim é o professor Malaca intimado a identificar, localizar e caracterizar as pronúncias cultas dos sete países signatários do AO, de modo a que a base IV seja exequível. (Texto 1)

(17) Para já, trata-se de instar quatro pessoas que considero e com quem tenho uma relação cordial, a que respondam aos pontos que levantei e aproveitem para ponderar as judiciosas considerações que sobre o assunto o Jornal de Angola tem publicado. Não perdem nada com o exercício. (Texto 2)

Nos textos em análise, o autor posiciona-se superiormente relativamente aos seus adversários - no primeiro texto, relativamente ao Professor João Malaca Casteleiro e, no segundo, a Pedro Santana Lopes, Jorge Bacelar Gouveia, António José Saraiva e Henrique Monteiro - conforme identifica, explicitamente, ao longo do texto.

Nas sequências de fecho apresentadas acima, o autor refere, objetivamente, a sua intenção de continuar este "diálogo" e, de alguma forma, perpetuar a polémica. De outra forma, as escolhas lexicais poderiam ser outras, evitando o uso de verbos agressivos como "intimar" ou "instar".

\section{Reflexões Finais}

O presente estudo permitiu mostrar, através da análise de dois exemplares de texto de opinião sobre o AO90, algumas estratégias de construção do discurso polémico.

Concluiu-se que o autor dos textos, Vasco Graça Moura, assumiu, desde o seu início, um ethos (Amossy, 1999) de superioridade, relativamente aos seus adversários, através de construções discursivas que continham diversos implícitos nesse mesmo sentido.

A natureza dialógica (Kerbrat-Orecchioni, 1980, 1992, 2001, 2005, entre outros) dos textos de opinião ficou visivelmente patente pelo recurso a atos iniciativos de pergunta, que permitem antever a vontade de continuar a discussão, alargar a polémica e, assim, perpetuar o dissenso. Também o recurso a citações ou paráfrases a textos anteriores deixou clara a natureza dialógica do discurso do autor.

Também o recurso a atos expressivos avaliativos, nomeadamente na expressão de opiniões desfavoráveis (Palrilha, 2009) acerca da implementação do AO90, permite perceber a total ausência de intenção de chegar a um consenso, conforme previsto por autores como Doury (2012), Amossy (2010) ou Burger (2005, 2008, 2011). 
Esses atos constituem, em si mesmos, atos ameaçadores da face (Goffman, 1959) que, desde que ativados, conseguem reforçar a intenção de perpetuar a polémica.

Ademais, a quase totalidade dos textos visa um ataque ad hominem, que pretende derrubar, nos dois casos, as diversas críticas de que o autor foi alvo, em publicações anteriores. É, possível, então, concluir que, mais do que um texto de opinião, o discurso construído é uma defesa através do ataque, não é uma discussão de ideias, mas uma desvalorização do "inimigo", um enfraquecimento da sua imagem.

Em suma, a construção do discurso polémico, nos dois textos em análise, e conforme previsto por KerbratOrecchioni (1980), baseia-se em estratégias de agressividade ou violência verbais, avaliações axiológicas fortes e processos de desqualificação do discurso do outro (Amossy, 2010). Através do presente estudo, com caráter exploratório, foi, pois, possível, e conforme referido por Rodrigues (2008), estudar alguns dos pontos mais importantes na construção da polémica verbal, como a análise dos atos de fala, dos atos ilocutórios ameaçadores da face, das marcas de subjetividade, das avaliações axiológicas, das retomas e da representação do Outro.

\section{Referências}

Amossy, Ruth (1999) Images de soi dans le discours. La construction de l'ethos. Lausanne: Delachaux et Niestlé.

Amossy, Ruth (2001) Introduction to the Study of Doxa. Poetics Today, Duke 23 (3), pp. 369-394. DOI: https://doi.org/10.1215/03335372-23-3-369

Amossy, Ruth (2002) Ethos at the Crossroads of Disciplines: Rhetoric, Pragmatics, Sociology. Poetics Today, Duke 22 (1), pp. 1-23. DOI: https://doi.org/10.1215/03335372-22-1-1

Amossy, Ruth (2008) Modalités argumentatives et registres discursifs: le cas du polemique. In. L. GaudinBordes \& G. Salvan (org.) Les registres. Enjeux stylistiques et visées pragmatiques. Louvain-la-Neuve: Academia Bruylant, pp. 93-102.

Amossy, Ruth (2010) The Functions of Polemical Discourse in the Public Sphere. In. M. Smith \& B. Warnick (org.) The Responsibilities of Rhetoric. Long Grove: Waveland Press, pp. 52-61.

Amossy, Ruth (2011) La coexistence dans le dissensus. La polémique dans les forums de discussion. Semen. Revue de Sémio-Linguistique des Textes et Discours, Besançon 31, pp. 25-42. DOI: https://doi.org/10.4000/semen.9051. Disponível em: www.journals.openedition.org. Acedido em: 3 jan. 2020.

Amossy, Ruth (2012) L'argumentation dans le discours, Paris: Armand Colin.

Angenot, Marc (2008) Dialogues de sourds: traité de rhétorique antilogique. Paris: Mille et Une Nuits.

Angenot, Marc (2015) Novas proposições para o estudo da argumentação na vida social. EID\&A: Revista Eletrônica de Estudos Integrados em Discurso e Argumentação, Ilhéus 3, pp. 142-155. Disponível em: www.periodicos.uesc.br/index.php/eidea/article/view/413. Acedido em: 3 fev. 2020.

Austin, John L. (1962) How to do Things with words. New York: Oxford University Press.

Brilliant, Maria (2011) L'émergence de la polémique autour de la formule « immigration choisie » dans la presse française (janvier-juillet 2005). Semen. Revue de Sémio-Linguistique des Textes et Discours, Besançon 31, pp. 113-128. DOI: https://doi.org/10.4000/semen.9105. Disponível em: www.journals.openedition.org. Acedido em: 3 jan. 2020.

Burger, Marcel (2005) La complexité argumentative d'une séquence de débat politique médiatique. In. Marcel Burger \& Martel Guylaine (org.) Argumentation et communication dans les médias. Québec: Nota Bene. pp. 51-79.

Burger, Marcel (2008) Analyzing the Linguistic Dimension of Globalization in Media Communication: the Case of Insults and Violence in Debates. In. P. Daniel \& E. L. Wyss (org.). Media Linguistics from a 
Concordar em discordar: análise discursivo-pragmática da polémica verbal em textos de opinião sobre o Acordo Ortográfico de 1990

European Perspective: Language Diversity and Medial Globalization in Europe. Basileia: VALS / ASLA, pp. $127-150$.

Burger, Marcel (2011) Une caractérisation praxéologique du désaccord polémique : ce qu'informer dans les médias veut dire. Semen. Revue de Sémio-Linguistique des Textes et Discours, Besançon 31, pp. 61-80. DOI: https://doi.org/10.4000/semen.9183. Disponível em: www.journals.openedition.org. Acedido em: 3 jan. 2020.

Castro, Ivo \& Isabel Leiria (1986) A demanda da ortografia portuguesa. Comentário do Acordo Ortográfico de 1986 e Subsídios para a Questão que lhe Seguiu. Lisboa: Edições João Sá da Costa.

Castro, Ivo (1987) Apresentação. In Ivo Castro, Inês Duarte \& Isabel Leiria (orgs.) A Demanda da Ortografia Portuguesa. Comentário do Acordo Ortográfico de 1986 e subsídios para a compreensão da Questão que lhe seguiu. Lisboa: Edições João Sá da Costa, pp. xi-xix.

Cavalcante, Mônica, Rosalice Pinto \& Mariza Brito (2018) Polêmica e Argumentação. Interfaces possíveis em textos midiáticos de natureza política. Diacrítica, Argumentação e Discursos, Braga, Portugal 32 (1), pp. 524. DOI: https://doi.org/10.21814/diacritica.140.

Charaudeau, Patrick (1995a) Une analyse sémiolinguistique du discours. Langages, Paris 117, pp. 96-111. DOI: https://doi.org/10.3406/lgge.1995.1708. Disponível em: www.patrick-charaudeau.com/Une-analysesemiolinguistique-du,64.html. Acedido em: 10 de janeiro de 2020.

Charaudeau, Patrick (1995b) Ce que communiquer veut dire. Revue des Sciences Humaines, [S.l.] 51, pp. 1-6. Disponível em: www.patrick-charaudeau.com/Ce-quecommuniquer-veut-dire.html. Acedido em: 10 fev. 2020.

Charaudeau, Patrick \& Dominique Maingueneau (2002) Dictionnaire d'Analyse du Discours. Paris: Éditions du Seuil.

Charaudeau, Patrick (2006) El contrato de comunicación en una perspectiva linguística: Normas psicosociales y normas discursivas. Opcion, Maracaibo, Venezuela 22 (49), pp. 38-54. Disponível em: www.dialnet.unirioja.es. Acedido em: 7 dez. 2019.

Costa, Joana Ferreira (2021) Afinal, o que é o populismo?. Disponível em https://www.ffms.pt/blog/artigo/85/afinal-o-que-e-o-populismo. Acedido em: 13 de jan. de 2021.

Cristóvão, Fernando (s.d.) Dicionário temático da Lusofonia. Lisboa: Texto Editores.

Dascal, Marcelo (2005) The balance of reason. In. D. Vanderveken (org.) Logic, Thought and Action. Netherlands: Springer, pp. 27-48. DOI: https://doi.org/10.1007/1-4020-3167-X_2.

De la Torre, Carlos (2003) Masas, Pueblo y democracia: Un balance crítico de los debates sobre el nuevo populismo. Revista de Ciencia Política XXIII 1, pp. 55-66.

Dockendorff, Andrés \& Vanessa Kaiser (2009) Populismo en América Latina. Una revisión de la literatura y la agenda. Revista Austral de Ciencias Sociales 17, pp. 75-100.

Doury, Marianne (2012) Preaching to the Converted. Why Argue When Everyone Agrees?. Argumentation, [S.1] 26 (1), pp. 99-114. DOI: https://org.doi.10.1007/s10503-011-9237-4.

Duarte, Isabel Margarida (2005) Falar Claro a Mentir. In. Dar a Palavra à Língua - Homenagem a Mário Vilela. Porto: Faculdade de Letras da Universidade do Porto, pp. 291-299.

Ducrot, Oswald et al. (1980) Les mots du discours. Paris: Minuit.

Emiliano, António (2008) Foi Você Que Pediu um Acordo Ortográfico?. Lisboa: Guimarães Editores.

Estrela, Edite (s.d.) A questão ortográfica. Reforma e acordos da Língua Portuguesa. Lisboa: Editorial Notícias.

Fonseca, Joaquim (1992) Linguística e texto/discurso: teoria, descrição, aplicação. Lisboa: Instituto de Cultura e Língua Portuguesa.

Fonseca, Joaquim (1994) Dimensão accional da linguagem e construção do discurso. In Linguística. Introdução, teoria e descrição do português. Porto: Porto Editora, pp. 127-128. Pragmática 
Fonseca, Joaquim (org.) (1998) A Organização e o funcionamento dos discursos. Estudos sobre o Português. Porto: Porto Editora. Tomos I, II, III.

Galito, Maria Sousa (2017) Populismo. Conceptualização do Fenómeno. Working Paper CEsA CSG 158/2017. Disponível em http://pascal.iseg.utl.pt/ cesa/index.php/menupublicacoes/working-papers Acedido em: 15 de jan. de 2021.

Gil, Isabel Fuzeta (2018) Discurso, conflito e argumentação. Das emoções no(s) discurso(s) em contexto referendário. Tese Doutoramento, Faculdade de Filosofia e Ciências Sociais da Universidade Católica Portuguesa.

Goffman, Erving (1967) Interaction ritual. Nova Iorque: Pantheon Books.

Gomes, Francisco Álvaro (2008) O Acordo Ortográfico. Porto: Edições Flumen.

Grice, H. Paul (1975) Logic and conversation. In. P. Cole \& J.L. Morgan (Eds.) Syntax and Semantics 3 Speech Acts. Academic Press, pp. 41-58.

Hermet, Guy (2001) Del populismo de los antíguos ao populismo de los modernos. In Del populismo de los antíguos al populismo de los modernos. México: El Colegio de México, Centro de Estudios Internacionais, pp. 13-34.

Jacquin, Jérôme (2011) Le/La polémique: une catégorie opératoire pour une analyse discursive et interactionnelle des débats publics?. Semen, Revue de Sémio-Linguistique des Textes et Discours, Bensançon 31, pp. 43-60. DOI: https://doi.org/10.4000/semen.9085. Disponível em: www.journals.openedition.org. Acedido em: 3 jan. 2020.

Kerbrat-Orecchioni, Catherine (1980) La polémique et ses définitions. La parole polemique. Lyon: Presses Universitaires de Lyon.

Kerbrat-Orecchioni, Catherine (1986) L'Implicite. Paris: Armand Colin, 2ème edition.

Kerbrat-Orecchioni, Catherine (1992) Les interactions verbales. T. I. Paris: A. Colin.

Kerbrat-Orecchioni, Catherine (2001) Les actes de langage dans le discours. Paris: Nathan Université.

Knight, Alan (1998) Populism and Neo-Populism in Latin America, Especially Mexico. Journal of Larin American Studies 30 (2), pp. 223-248.

Laclau, Ernesto (1987) Populismo y transformación del imaginario político en América Latina. A Jorunal of Latin American na Caribbean Studies 42, pp. 25-38.

Laclau, Ernesto (2005) La Razón Populista. Méxixo DF: Fondo de Cultura Económica.

Laclau, Ernesto (2006) La deriva populista y la centro izquierda latino-americana. In. Nueva Sociedad 205, pp. 57-65.

Maingueneau, Dominique (1983) Sémantique de la polémique. Lausanne: Éditions l’Âge de l'Homme.

Maingueneau, Dominique (1984) Genèses du discours. Bruxelles: Pierre Mardaga.

Maingueneau, Dominique (1991) L'analyse du discours. Paris: Hachette.

Maingueneau, Dominique (2002) Problème d'ethos. Pratiques, Paris 113, p. 55-68. DOI: https://doi.org/10.3406/prati.2002.1945.

Maingueneau, Dominique (2005) As categorias da análise do discurso. In. F. M. Menéndez (org.) Análise do Discurso. Lisboa: Hugin Editores, pp. 82-105.

Malaca Casteleiro, João \& Pedro Dinis Correia (2007) Atual. O novo acordo ortográfico. Lisboa: Texto Editora.

Marques, Maria Aldina (2000) Funcionamento do discurso político parlamentar: a organização enunciativa no debate de interpelação ao governo. Tese de doutoramento, CEHUM/ Universidade do Minho.

Mauai, Ângelo Américo (2015) Elementos para uma análise linguística do discurso realizado em situação de entrevista: contributos para o seu estudo semântico-pragmático. Dissertação de Mestrado, Universidade Aberta). $\quad$ Disponível em https://repositorioaberto.uab.pt/bitstream/10400.2/4394/1/TMEPM_AngeloMauai.pdf. Acedido a 6 de março de 2021. 
Concordar em discordar: análise discursivo-pragmática da polémica verbal em textos de opinião sobre o Acordo Ortográfico de 1990

Micheli, Raphaël (2011) Quand l'affrontement porte sur les mots en tant que mots: polémique et réflexivité langagière. Semen, Revue de Sémio-Linguistique des Textes et Discours, Bensançon 31, pp. 97-112. DOI: https://doi.org/10.4000/semen.9164. Disponível em: www.journals.openedition.org. Acedido em: 3 jan. 2020.

Mude, Cas \& Cristobal Kaltwasser (2017) Populismo. Uma brevíssima Introdução. Gradiva.

Ninitas, Mariana (2020) 'Troca de galhardetes'. Para o estudo da violência verbal na polémica sobre o Acordo ortográfico em Portugal In Revista de Estudos de Linguagem, Violência Verbal 28 (4). Belo Horizonte/Minas Gerais, pp. 1873-1912.

Palma, Eliana Botelho (2010) Acordo Ortográfico: um puzzle de oito cabeças. Dissertação Mestrado, Faculdade de Ciências Sociais e Humanas da Universidade Nova de Lisboa.

Palrilha, Silvéria Ramos (2009) Contributos para a análise dos actos ilocutórios expressivos em português. Dissertação de Mestrado em Linguística e Ensino, Universidade de Coimbra. Disponível em: http://www.uc.pt/uid/celga/recursosonline/dissertacoes/dissertacoesdemestrado/silveriamariaramospalrila. Acedido em: 28 dez. 2019.

Ramos, Rui (2000) O discurso de opinião como discurso polémico: aspectos da sua configuração e da interacção social. Cadernos do Noroeste 14 (1-2), pp. 235-247. DOI: https://org.doi.10.17231/comsoc.2(2000).1398

Ricardo, D. (s/d) O Novo Acordo Ortográfico. Lisboa: Lisgráfica.

Ribeiro, H. M. S. N. (1994) Da linguagem em questão à questão da linguagem, reflexões a propósito da polémica sobre o "Acordo Ortográfico". Dissertação Mestrado, Faculdade de Ciências Sociais e Humanas da Universidade Nova de Lisboa.

Roberts, Kenneth (1999) El neoliberalismo y la transformación del populismo en América Latina. El caso peruano. In. Populismo y neopopulismo en América Latina; el problema de la Cenicienta. Buenos Aires: Editorial Univerisitaria, pp. 375-408.

Rodrigues, Sónia Valente (2008) Estrutura e funcionamento da interacção verbal polémica. Contributo para o estudo da polemicidade em Camilo Castelo Branco. Tese Doutoramento, Faculdade de Letras, Universidade do Porto.

Searle, John R. (1969) Speech Acts: An Essay in the Philosophy of Language. Cambridge: Cambridge University Press. DOI: https://doi.org/10.1017/CBO9781139173438

Seara, Isabel R. \& Isabelle Simões Marques (2015) Guerre ou paix autour de l'accord orthographique au Portugal. Étude des modalités dans les polemiques verbales. In. M. H. Araújo Carreira (org.) Faits de langue et de discours pour l'expression des modalités dans les langues romanes. Paris: Université Paris 8 Vincennes Saint-Denis, n. 60, p. 435-455.

Weyland, Kurt (2001) Clarifying a Contested Concept: Populism in the Study of Latin American Politics. In. Comparative Politics 34 (1), pp. 1-22. 
Anexos

Anexo 1.

\begin{tabular}{|c|c|c|}
\hline Jornal: Diário de Notícias & Título: Intimação ao professor Malaca & Data: $08 / 02 / 12$ \\
\hline \multicolumn{2}{|l|}{ Autor: Vasco Graça Moura } & Código: Texto 1 \\
\hline
\end{tabular}

\section{Intimação ao Professor Malaca}

Num esgar de arrogância despeitada, o Prof. João Malaca Casteleiro diz ao Expresso de sábado passado, sobre a minha tomada de posição contra o Acordo Ortográfico: "É um autêntico disparate e uma atitude mesquinha, revelando espírito de vingança. Quem vai pagar estes custos?".

Tenho pouca paciência para os trejeitos do autor de um livro intitulado O Novo Acordo Ortográfico, que não li, não tenciono ler e achei, de resto, perfeitamente detestável. Num gesto largo e moscovita, deixo essa ocupação para a moleirinha ociosa do Dr. António José Seguro que decerto muito lucrará com isso.

O professor Malaca tem-se especializado em produções de medíocre qualidade, como o famigerado e redutor dicionário da Academia das Ciências, abominável exercício de encolhimento do português contemporâneo, de cuja revisão ele parece agora ter sido dispensado. Mas não vale a pena gastar cera com ruins defuntos. E quanto a quem paga custos e que custos, estamos conversados...

Também não vale a pena tratá-lo como interlocutor capaz quanto a questões jurídico-constitucionais relativas à recepção na ordem interna dos tratados e convenções internacionais. Prefiro poupá-lo aos custos desse ingente esforço intelectual.

Mas já vale a pena intimar o professor Malaca a responder muito concretamente aos pontos seguintes:

$\mathrm{O}$ art. ${ }^{\circ}$ 2. ${ }^{\circ}$ do AO dispõe: "Os Estados signatários tomarão, através das instituições e órgãos competentes, as providências necessárias com vista à elaboração, até 1 de Janeiro de 1993, de um vocabulário ortográfico comum da língua portuguesa, tão completo quanto desejável e tão normalizador quanto possível, no que se refere às terminologias científicas e técnicas."

Sendo certo que o prazo inicialmente referido foi modificado, deve o professor Malaca responder sem subterfúgios onde é que está esse vocabulário comum.

Não existindo esse vocabulário comum, deve dizer sem subterfúgios onde é que está a plataforma ou instância formada por instituições e órgãos competentes dos Estados signatários, com o mandato e o objectivo de elaborá-lo, qual o seu calendário de reuniões e qual o teor daquilo que tenha deliberado.

Ainda quanto a este aspecto, deve responder, sempre sem subterfúgios, quais são, em Portugal e nos outros países as instituições e órgãos competentes para o efeito.

Caridosamente, informo-o de que não vale a pena fazer batota: em Portugal, a instituição competente é a Academia das Ciências, o que o Governo Sócrates esqueceu em patente violação da lei, e não o ILTEC (Instituto de Linguística Teórica e Computacional), que é um simples instituto universitário e não tem qualquer competência formal ou institucional na matéria (tem financiamentos da FCT cujos montantes podem ser objecto de indagação, já que o professor Malaca se mostra tão preocupado com custos).

Supondo que ele respondeu correctamente às questões que antecedem, fica intimado a explicar também como é que entende que o AO de 1990 pode ser aplicado sem a verificação desse pressuposto.

A segunda ordem de questões prende- -se com regras do próprio AO.

Diz a al. c) do n. ${ }^{\circ} 1$ da Base IV do AO que o c, com valor de oclusiva velar, das sequências interiores cc (segundo c com valor de sibilante), cç e ct, e o p das sequências interiores pc (c com valor de sibilante), pç e pt, se conservam ou eliminam "facultativamente, quando se proferem numa pronúncia culta, quer geral quer restritamente, ou então quando oscilam entre a prolação e o emudecimento: aspecto e aspeto, cacto e cato, 
Concordar em discordar: análise discursivo-pragmática da polémica verbal em textos de opinião sobre o Acordo Ortográfico de 1990

caracteres e carateres, dicção e dição; facto e fato, sector e setor; ceptro e cetro, concepção e conceção, corrupto e corruto, recepção e receção".

Sendo assim, é o professor Malaca intimado a esclarecer, imediatamente e sem subterfúgios, se a aplicação de uma ferramenta de conversão automática que elimine na prática a possibilidade de opção entre essas facultatividades corresponde a cumprir o AO.

E por fim é o professor Malaca intimado a identificar, localizar e caracterizar as pronúncias cultas dos sete países signatários do AO, de modo a que a base IV seja exequível.

Por decisão pessoal, o autor do texto não escreve segundo o novo Acordo Ortográfico

\begin{tabular}{|c|c|c|}
\hline Jornal: Diário de Notícias & Título: Questões do Estado de Direito & Data: $22 / 02 / 12$ \\
\hline \multicolumn{2}{|l|}{ Autor: Vasco Graça Moura } & Código: Texto 2 \\
\hline
\end{tabular}

\section{Questões do Estado de Direito}

O que é que haverá de comum entre personalidades tão diferentes como Pedro Santana Lopes, Jorge Bacelar Gouveia, José António Saraiva e Henrique Monteiro? Face aos jornais das últimas semanas, a resposta é muito simples: todos defendem o Acordo Ortográfico, todos discordam das posições que tenho sustentado, todos, pelos vistos, entraram em alerta vermelho com os textos publicados no Jornal de Angola, e todos evitam tomar posição sobre questões que são essenciais.

A primeira dessas questões é a da entrada em vigor do AO. Toda a gente sabe que, não tendo sido ratificado pelas Repúblicas Populares de Angola e de Moçambique, ele não entrou em vigor.

A ratificação é o acto pelo qual um estado adverte a comunidade internacional de que se considera obrigado nos termos do tratado que subscreveu juntamente com outros estados. No que a este caso interessa, o tratado entra em vigor na ordem jurídica internacional logo que ratificado por todos os estados signatários. A partir do momento em que entre em vigor na ordem jurídica internacional, essa convenção será recebida na ordem jurídica interna do estado signatário. Antes, não pode sê-lo.

Não estando em vigor na ordem jurídica internacional, nem ele nem, por identidade de razão, o bizarro segundo protocolo modificativo, uma vez que também não foi ratificado por aqueles estados, o AO não está nem pode estar em vigor na ordem jurídica portuguesa.

Nenhuma das individualidades referidas toma posição quanto a este ponto.

Ora, sem o AO estar em vigor, a solução é muito simples: continua a vigorar a ortografia que se pretendia alterar. Como estamos num estado de Direito, a solução é só essa e mais nenhuma. E a lei deve ser cumprida por todos.

A segunda questão prende-se com a exigência, feita pelo próprio AO (art. ${ }^{\circ} 2^{\circ}$ ), de um vocabulário ortográfico comum, elaborado com a participação de instituições e órgãos competentes dos estados signatários. Não existe. Qualquer outro vocabulário que se pretenda adoptar, seja ele qual for, será uma fraude grosseira ao próprio acordo...

A resolução do Conselho de Ministros do Governo Sócrates (n. ${ }^{\circ} 8 / 2011$, de 25 de Janeiro) raia os contornos de um caso de polícia correccional: produz uma distorção ignóbil da verdade ao afirmar, no preâmbulo, que adopta “o Vocabulário Ortográfico do Português, produzido em conformidade com o Acordo Ortográfico". É falso.

Nenhuma das individualidades referidas toma posição quanto a este ponto. 
Mesmo que entendessem que o AO está em vigor, uma coisa é certa: nenhum entendimento, nenhum diploma, nenhum sofisma político ou jurídico pode dar existência àquilo que não existe.

Sendo assim, e não se podendo aplicar o AO por falta de um pressuposto essencial à sua aplicabilidade, continua em vigor a ortografia que se pretendia alterar por via dele. Como estamos num estado de Direito, a solução é só essa e mais nenhuma. E a lei deve ser cumprida por todos.

O grande problema é portanto o de que cumprir o Acordo Ortográfico, no presente estado de coisas do nosso estado de Direito, implica não o aplicar! Ou, dizendo por outras palavras, fazer de conta que se aplica o AO é violá-lo pura e simplesmente, na sua letra e no seu espírito...

Nenhuma das individualidades referidas toma posição quanto a esta situação paradoxal de que, certamente, tiveram a argúcia de se aperceber.

De resto, há muitas outras questões que têm sido levantadas, mas que as mesmas individualidades se dispensam de considerar, mostrando uma suficiência assaz discutível em relação a assuntos que não estudaram e de que, pelos vistos, percebem pouco. Não as abordaremos para já, mas elas não perdem pela demora. Digase apenas que nem mesmo o Brasil aceita a carnavalização da grafia que está a ser praticada em Portugal!

Acrescento que estou um tanto ou quanto farto de ter de voltar a estas coisas com alguma frequência. Mas tenho mais apego à minha língua do que a muitos outros interesses pessoais. E voltarei ao assunto as vezes que for preciso.

Para já, trata-se de instar quatro pessoas que considero e com quem tenho uma relação cordial, a que respondam aos pontos que levantei e aproveitem para ponderar as judiciosas considerações que sobre o assunto o Jornal de Angola tem publicado. Não perdem nada com o exercício. 